\title{
JPEB
}

Jurnal Penelitian Ekonomi dan Bisnis, 4 (2), 2019, Hal: 174-179

http://www.jpeb.dinus.ac.id

\section{PENGARUH IMPLEMENTASI SHARIA EDUGAME TERHADAP PERFORMANCE LITERACY PENDIDIK TK ISLAM HIDAYATULLAH SEMARANG}

\author{
Imam Nuryanto $^{1^{*}}$, Ida Farida ${ }^{2}$ dan Guruh Taufan Hariyadi ${ }^{3}$ \\ ${ }^{1,2,3}$ Program Studi Manajemen, Universitas Dian Nuswantoro Semarang \\ Jalan Nakula I No.5-11 Semarang, Indonesia \\ *Corresponding Email : imam.udinus@gmail.com
}

Diterima: Mei 2019; Direvisi: Agustus 2019; Dipublikasikan: September 2019

\begin{abstract}
Sharia Edugame is an information technology-based educational media with islamic content. Sharia Edugame is expected to be a learning media that supports early childhood education. Edugame has 7 indicators, namely overall value, usability, accuracy, appropriateness, relevance, objectives and feed back. The purpose of this study was to determine the effect of implementing sharia edugame on educator literacy performance. The object chosen in this study was the TK Islam Hidayatullah Semarang. The sampling technique used was a saturated sample with a total of 21 educators. The data in this study were obtained by questionnaire method which was filled independently. The analysis used in this study uses simple linear regression analysis. The results of this study prove and give the conclusion that the implementation of sharia edugame has a positive and significant effect on performance literacy.
\end{abstract}

Keywords:Sharia Edugame; Islamic Content; Performance Literacy

\section{ABSTRAK}

Sharia Edugamemerupakan media pendidikan berbasis teknologi informasi dengan islamic content. Sharia Edugame diharapkan menjadi media pembelajaran yang mendukung pendidikan anak usia dini. Edugame memiliki 7 indikator, yaitu overall value, usability, accuracy, appropriateness, relevance, objectives dan feed back. Tujuan dari penelitian ini adalah untuk mengetahui pengaruh implementasi sharia edugame terhadap performance literacy pendidik. Objek yang dipilih pada penelitian ini adalah TK Islam Hidayatullah Semarang. Teknik pengambilan sampel yang digunakan yakni sampel jenuh dengan jumlah 21 pendidik. Data pada penelitian ini diperoleh dengan metode kuesioner yang diisi secara mandiri. Analisis yang digunakan dalam penelitian ini menggunakan analisis regresi linier sederhana. Hasil dari penelitian ini membuktikan dan memberi kesimpulan bahwa implementasi sharia edugame berpengaruh positif dan signifikan terhadap performance literacy.

Kata Kunci: Sharia Edukasi Game; Konten Islam; Performance Literacy 


\section{PENDAHULUAN}

Ilmu pengetahuan dan teknologi dewasa ini berkembang sangat cepat, khususnya di bidang teknologi informasi, salah satu fungsi teknologi informasi di sektor pendidikan yaitu sebagai media pembelajaran, sebagai contoh salah satu penerapan teknologi informasi dalam bidang pendidikan yaitu dalam bentuk permainan edukasi (edugame) sebagai media pembelajaran.Perkembangan teknologi informasi pada berbagai bidang, baik itu dari sisi perangkat lunak (software) maupun perangkat keras (hardware) seperti perangkat komputer khususnya pada bidang multimedia interaktif. Salah satu perangkat lunak yang dikembangkan dan mendukung pembuatan media pembelajaran adalah powerpoint show (pps). Perangkat lunak tersebut dapat digunakan untuk membuat sebuah game maupun animation. Edukasi tidak hanya berupa pelajaran. Menurut Rachman (2012) game bersifat entertain atau menghibur, sehingga penggunaan game sebagai media pembelajaran sangat tepat untuk pendidikan anak usia dini.

Tidak semua edugame cocok diterapkan dalam pendidikan, terutama lembaga pendidikan islam. Salah satunya adalah TK Islam Hidayatullah yang menerapkan Agama Islam sebagai pegangan utama pendidikan Agamanya. Sharia Edugame merupakan media pendidikan berbasis teknologi informasi dengan islamic content, memiliki visualisasi yang menarik, sehingga peserta didik dengan mudah menerima dan mengetahui informasi yang disampaikan. Sharia Edugame diharapkan menjadi media pembelajaran yang mendukung pendidikan anak usia dini. Edugame memiliki 7 indikator, yaitu overall value, usability, accuracy, appropriateness, relevance, objectives dan feed back.

Untuk mengetahui manfaat implementasi media pembelajaran dalam hal ini sharia edugame terhadap performance literacy pendidik, perlu diadakan penelitian. Hal ini dimaksudkan untuk mengetahui apakah media pembelajaran berupa sharia edugame dapat menunjang kinerja (performance) pendidik sesuai dengan apa yang diharapkan. Berdasarkan uraian diatas, peneliti tertarik untuk melaksanakan penelitian mengenai implementasi sharia edugame terhadap performance literacy pendidik TK Islam Hidayatullah Semarang.

\section{TINJAUAN PUSTAKA \\ Performance Mangement}

Kinerja suatu organisasi hendaknya dapat dipahami secara sama baik oleh manajemen maupun stakeholder, terutama direct users. Menurut Kristiyanti (2012) Melalui suatu pengukuran kinerja, keberhasilan suatu organisasi akan lebih dilihat dari kemampuan instansi tersebut berdasarkan sumber daya yang dikelolanya untuk mencapai hasil sesuai dengan rencana yang telah dituangkan dalam perencanaan tujuan organisasi. Pengukuran kinerja adalah suatu proses penilaian kemajuan pekerjaan terhadap tujuan dan sasaran yang telah ditentukan sebelumnya, termasuk informasi atas: efisiensi penggunaan sumber daya dalam menghasilkan barang dan jasa, kualitas barang dan jasa (seberapa baik barang dan jasa diserahkan kepada pelanggan dan sampai seberapa jauh pelanggan terpuaskan), hasil kegiatan dibandingkan dengan maksud yang diinginkan, dan efektivitas tindakan dalam mencapai tujuan (Robertson, 2002).

\section{Performance Literacy}

Kinerja (performance) adalah gambaran mengenai tingkat pencapaian pelaksanaan suatu kegiatan, program, kebijakan dalam mewujudkan sasaran, tujuan, misi dan visi organisasi yang tertuang dalam strategic planning suatu organisasi. Kinerja sering digunakan untuk menyebut prestasi atau tingkat keberhasilan individu maupun kelompok individu. Kinerja literasi yang dimaksud adalah literasi digital, dimana mengukur kecakapan atau pemahaman seseorang (pendidik) dalam menggunakan media digital, dalam penelitian ini media digital adalah media pembelajaran yang berupa sharia edugame. 
Imam Nuryanto, Ida Farida dan Guruh Taufan Hariyadi : Pengaruh Implementasi Sharia Edugame Terhadap Performance Literacy Pendidik Tk Islam Hidayatullah Semarang

Kompetensi aktif seseorang yang memiliki kemampuan literasi digital, yang terdiri atas menggunakan, memahami, dan memproduksi konten. Sehingga dalam penelitian ini menggunakan 3 indikator yaitu use, understand dan create.

\section{Educational Game (edugame)}

Game edukasi (edugame) adalah game yang dirancang untuk pengayaan pendidikan mendukung pengajaran dan pembelajaran, menggunakan teknologi multimedia interaktif. Menurut Hurd dan Jenuings dalam Rachman (2012) menyatakan bahwa perancang edugameyang baik haruslah memenuhi kriteria dari educational game itu sendiri. Berikut ini adalah beberapa kriteria dari sebuah educational game, yaitu :

a. Nilai keseluruhan (overall value). Nilai keseluruhan dari suatu game terpusat pada desain dan panjang durasi game. Edugame ini dibangun dengan desain yang menarik dan interaktif. Untuk penentuan panjang durasi, edugame ini menggunakan batasan waktu yang dianjurkan dalam menggunakannya.

b. Kemampuan penggunaan (usability). Mudah digunakan dan diakses adalah poin penting bagi perancang game. Edugame ini dirancang dengan sistem interface yang user friendly sehingga user dengan mudah dapat mengaksesnya.

c. Keakuratan (accuracy). Keakuratan diartikan sebagai bagaimana kesuksesan model atau gambaran sebuah game dapat dituangkan ke dalam percobaan atau perancangan. Perancangan edugame ini harus sesuai dengan model game pada tahap perencanaan.

d. Kesesuaian (appropriatieness). Kesesuaian dapat diartikan bagaimana isi dan desain game dapat diadaptasikan terhadap keperluan user dengan baik. Edugame ini menyediakan menu dan fitur yang diperlukan user untuk membantu pemahaman user dalam menggunakannya.

e. Relevan (relevance). Relevan artinya dapat mengaplikasikan isi game ke target user. Agar dapat relevan terhadap user, sistem harus membimbing userdalam pencapaian tujuan pembelajaran. Karena edugame ini ditujukan untuk anak-anak, maka desain antarmuka harus sesuai dengan nuansa anak-anak, yaitu menampilkan warna-warna yang ceria.

f. Objektifitas (objectives). Objektivitas menentukan tujuan user dan kriteria dari kesuksesan atau kegagalan. Dalam edugame ini objektivitas adalah usaha untuk mempelajari hasil luaran dari game.

g. Umpan balik (feedback). Untuk membantu pemahaman user bahwa kinerja dari edugame sesuai dengan objek game atau tidak, feedback harus disediakan. Edugame ini menyajikan animasi efek suara yang mengindikasikan kesuksesan atau kegagalan.

\section{Sharia Edugame}

Sharia Edugame merupakan media pendidikan berbasis teknologi informasi dengan islamic content, memiliki visualisasi yang menarik, sehingga peserta didik dengan mudah menerima dan mengetahui informasi yang disampaikan. Sharia Edugame diharapkan menjadi media pembelajaran yang mendukung pendidikan anak usia dini. Berikut ini adalah beberapa kriteria dari sebuah shariaeducational game, yaitu : Pertama, nilai keseluruhan (overall value)Sharia Edugamememiliki desain yang menarik dan interaktif. Kedua, kemampuan penggunaan (usability) Sharia Edugame mudah digunakan. Ketiga, keakuratan (accuracy) Sharia Edugame sesuai dengan rancangan media pembelajaran islamic content. Keempat, kesesuaian (appropriatieness) Sharia Edugame sesuai dengan media pembelajaran islamic content. Kelima, relevan (relevance) Sharia Edugame sesuai dengan pembelajaran anak-anak. Keenam, objektifitas (objectives) Sharia Edugame sesuai dengan pendidikan anak-anak. Sedangkan Ketujuh kriteria umpan balik (feedback) Sharia Edugame memiliki tampilan feedback yang baik. 


\section{METODE PENELITIAN}

Jenis penelitian ini menggunakan survei lapangan (field research), karena tujuan penelitian ini adalah mengukur persepsi pendidik atas produk sharia edugame. Penelitian ini merupakan jenis penelitian deskriptif kuantitatif. Data yang digunakan yakni data primer yang berasal dari hasil respon responden melalui penyebaran kuesioner. Setelah memperoleh data, langkah selanjutnya adalah mengolah data menggunakan uji statistik dan menginterpretasikan hasilnya. Tujuan penelitian yakni mengetahui tingkat penerimaan responden terhadap produk sharia edugame yang peneliti tawarkan. Oleh sebab itu, peneliti menggunakan populasi pendidik yang concern dibidang Pendidikan Islam di daerah Semarang. Teknik pengambilan sampel yang digunakan yakni sampel jenuh (saturation sampling) dengan jumlah 21 pendidik TK Islam Hidayatullah Semarang. Metode pengumpulan data yang dipilih peneliti yaitu melalui kuesioner, dimana kuesioner diisi setelah responden mengimplementasikan produk sharia edugame. Interval nilai yang digunakan peneliti yaitu skala likert 1-5, dari jawaban Sangat Tidak Setuju (STS). Tidak Setuju (TS), Netral (N), Setuju (S) dan Sangat Setuju (SS). Analisis yang digunakan dalam penelitian ini menggunakan analisis Regresi Linier Sederhana. Sehingga dapat digambarkan kerangka konseptual sebagai berikut :

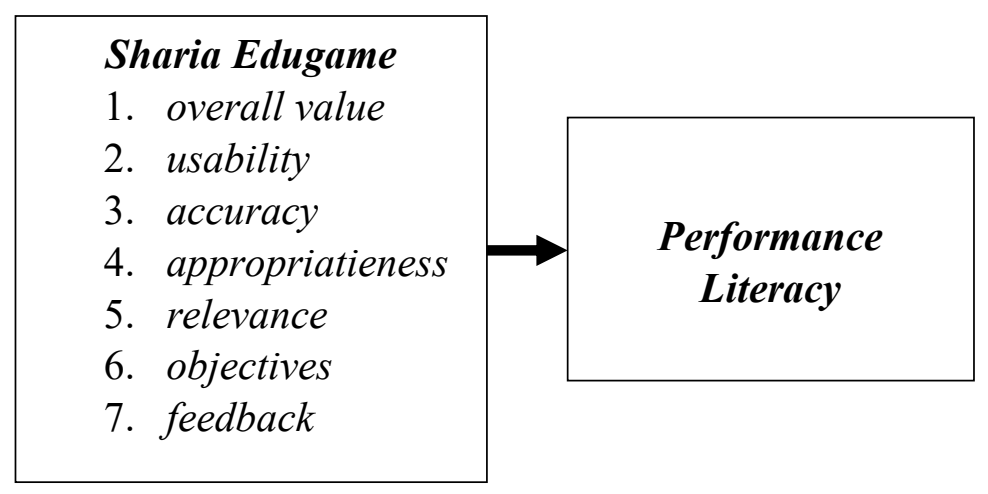

\section{Gambar 1. Kerangka Konseptual}

\section{HASIL DAN PEMBAHASAN}

Tabel 1. Tabel Correlations

\begin{tabular}{llcc}
\hline & & $\begin{array}{c}\text { PERFOR } \\
\text { MANCE }\end{array}$ & $\begin{array}{c}\text { SHARIA_ } \\
\text { EDUGAME_ } \\
\text { LITERACY }\end{array}$ \\
\hline $\begin{array}{l}\text { Pearson } \\
\text { Correlation }\end{array}$ & $\begin{array}{l}\text { PERFORMANCE } \\
\text { SHARIA_EDUGAME_L } \\
\text { ITERACY }\end{array}$ & $\begin{array}{c}1.000 \\
983\end{array}$ & 1.000 \\
\hline $\begin{array}{l}\text { Sig.(1- } \\
\text { tailed) }\end{array}$ & PERFORMANCE & & \\
& SHARIA_EDUGAME_L & .000 & .000 \\
\hline $\mathbf{N}$ & ITERACY & & \\
& PERFORMANCE & 21 & 21 \\
& SHARIA_EDUGAME_L & 21 & 21 \\
& ITERACY & & \\
\hline
\end{tabular}

Keterangan :

Dari tabel Correlations tersebut, dapat diketahui bahwa nilai $r$ hitung adalah 0,983 Angka ini menunjukkan korelasi yang kuat antara variabel $\mathrm{X}$ dan variabel $\mathrm{Y}$.

Sig. $(1$-tailed $)=0,000$ menunjukkan hubungan yang signifikan karena $0,000<0,05$ dimana 0,05 merupakan taraf signifikan. 
Imam Nuryanto, Ida Farida dan Guruh Taufan Hariyadi : Pengaruh Implementasi Sharia Edugame Terhadap Performance Literacy Pendidik Tk Islam Hidayatullah Semarang

$\mathrm{N}$ merupakan jumlah data dari masing-masing variabel.

Tabel 2. Tabel Model Summary

\begin{tabular}{ccccc}
\hline Model & $\mathbf{R}$ & $\begin{array}{c}\text { R } \\
\text { Square }\end{array}$ & $\begin{array}{c}\text { Adjust R } \\
\text { Square }\end{array}$ & $\begin{array}{c}\text { Std. Error Of } \\
\text { The Estimate }\end{array}$ \\
\hline 1 & $.983^{\mathrm{a}}$ & .966 & .965 & .05075 \\
\hline
\end{tabular}

$\mathrm{R}$ merupakan koefisien korelasi dimana dalam kasus ini besarnya $\mathrm{R}$ adalah 0,983 . $\mathrm{R}$ Square merupakan koefisien determinasi. Dalam kasus ini, besar R Square $\left(\mathrm{R}^{2}\right)$ adalah $0,966=$ $96,6 \%$. Artinya, besarnya pengaruh variabel X terhadap Y adalah $96,6 \%$ dan besarnya variabel lain yang memengaruhi variabel $\mathrm{Y}$ adalah sebesar 3,4\%). Adjusted $\mathrm{R}$ Square merupakan nila $\mathrm{R}^{2}$ yang disesuaikan. Std. Error of the Estimation merupakan ukuran kesalahan standar dari penaksiran.

Tabel 3. Tabel ANOVA

\begin{tabular}{clccccc}
\hline Model & & $\begin{array}{c}\text { Sum of } \\
\text { Squares }\end{array}$ & df & $\begin{array}{c}\text { Mean } \\
\text { Square }\end{array}$ & F & Sig. \\
\hline $\mathbf{1}$ & Regression & 1.411 & 1 & 1.411 & 547.998 & $.000^{\mathrm{a}}$ \\
\hline & Residual & .049 & 19 & .003 & & \\
\hline & Total & 1.460 & 20 & & & \\
\hline
\end{tabular}

Keterangan :

Tabel ANOVA ini menampilkan nila $F$ hitung, yaitu sebesar 547.998.

$\begin{array}{lll}\text { df pembilang } & =\text { jumlah variabel }-1 & =2-1=1 \\ \text { df penyebut } & =\text { jumlah data }- \text { jumlah variabel } & =21-2=19 \\ \text { df Total } & =\text { df pembilang }+ \text { df penyebut } & =1+19=20\end{array}$

Tabel 4. Tabel Regresi

\begin{tabular}{llcccccc}
\hline Model & & \multicolumn{2}{c}{$\begin{array}{c}\text { Unstandardized } \\
\text { coefficients }\end{array}$} & $\begin{array}{c}\text { Standardized } \\
\text { Coefficients }\end{array}$ & t & Sig. \\
\cline { 3 - 6 } & & B & $\begin{array}{c}\text { Std. } \\
\text { Error }\end{array}$ & Beta & & \\
\hline $\mathbf{1}$ & & & & & \\
\hline & (Constant) & 1.044 & .161 & & 6.475 & .000 \\
\hline & SHARIA_E & .905 & .039 & .983 & 23.409 & .000 \\
& DUGAME & & & & & \\
\hline & LITERACY & & & & & \\
\hline
\end{tabular}

Persamaan Regresi $\mathrm{Y}=1,044+0,905 \mathrm{X}$ menyatakan bahwa jika tidak ada kenaikan nilai dari variabel $\mathrm{X}$, nilai variabel $\mathrm{Y}$ adalah 1,044 . Koefisien regresi sebesar 0,905 menyatakan bahwa setiap penambahan satu nilai pada variabel $\mathrm{X}$ akan memberikan kenaikan skor sebesar 0,905 .

Hipotesis

Ho : Tidak ada pengaruh yang signifikan antara variabel $\mathrm{X}$ dan variabel $\mathrm{Y}$.

$\mathrm{Ha}$ : Terdapat pengaruh yang signifikan antara variabel X dan variabel Y.

Dasar pengambilan Keputusan.

1. Jika nilai probabilitas lebih kecil daripada atau sama dengan nilai probabilitas Sig, $(0,05 \leq$ Sig. $)$, Ho diterima (Ha ditolak). Artinya, tidak signifikan.

2. Jika nilai probabilitas lebih besar daripada atau sama dengan nilai probabilitas Sig. $(0,05 \geq$ Sig. $)$, Ho ditolak (Ha diterima). Artinya, signifikan. 
Hasil uji signifikansi pada tabel ANOVA menunjukkan nilai Sig. Sebesar 0,000. Jika dibandingkan dengan $\alpha=0,05$, nilai Sig. Lebih kecil daripada $\alpha(\operatorname{Sig} \leq \alpha)$, yaitu $0,000 \leq 0,05$. Artinya, Ho ditolak dan Ha diterima. Dengan demikian, hal ini menunjukkan bahwa variabel $\mathrm{X}$ berpengaruh secara signifikan terhadap variabel $\mathrm{Y}$.

\section{SIMPULAN}

Analisis yang digunakan dalam penelitian ini menggunakan Regresi Linier Sederhana. Hasil dari penelitian ini membuktikan dan memberi kesimpulan bahwa: implementasi sharia edugame berpengaruh positif dan signifikan terhadap performance literacy. Persamaan Regresi $\mathrm{Y}=1,044+0,905 \mathrm{X}$ menyatakan bahwa jika tidak ada kenaikan nilai dari variabel $\mathrm{X}$, nilai variabel $Y$ adalah 1,044. Koefisien regresi sebesar 0,905 menyatakan bahwa setiap penambahan satu nilai pada variabel $\mathrm{X}$ akan memberikan kenaikan score sebesar 0,905. Dalam penelitian implementasi sharia edugame mendapat nilai rata-rata 4.161 yang artinya BAIK, sedangkan performance literacy mendapat nilai rata-rata 4.809 yang artinya SANGAT BAIK. Sehingga hasil penelitian ini diharapkan Sharia Edugame menjadi media pembelajaran yang mendukung pendidikan anak usia dini.

\section{DAFTAR PUSTAKA}

Awwal, dkk. 2018. Sharia Economics Edugame (SEE) : Alternatif Pengembangan Pemahaman Literasi Keuangan Syariah. Jurnal Studi Agama dan Masyarakat 14 (01): 64-71

Junaidi. 2015. Pengaruh Pemanfaatan Media Pembelajaran terhadap Kinerja. Widyaiswara Teknis Balai Diklat Keagamaan Semarang.

Kristiyanti, Mariana. 2012. Peran Indikator Kinerja dalam mengukur Kinerja Manajemen. Majalah Ilmiah Informatika. 3 (3).

Media Awareness Network. Skema Kompetisi Aktif Digital Literacy. http://www.mediaawareness.ca/english/corporate/media_kit/digital_literacy_paper_pdf/digitalliteracypa per_part1.pdf.

Morissan. 2012. Metode Penelitian Survei.Jakarta: Kencana.

Nugraheny dan Destiranti. 2016. Penerapan Edugame Interaktif untuk Pengenalan Pakaian Adat Nasional Indonesia. Jurnal Simetris. 7 (1).

Rachman, H. 2012. Game Edukasi. Yogyakarta : Andi Offset

Robertson, Gordon. 2002. Revie Kinerja. Lokakarya Revie Kinerja. BPKP dan Executive Education.

Scot, Thomas W. and P. Tiessen. 1999. Performance Measurement and Managerial Teams, Accounting, Organizations and Society.

Sugiyono. 2014. Metode Penelitian Kuantitas dan $R \&$ D. Bandung: Alfabeta.

Widiastuti, dkk. 2012. Membangun Game Edukasi, Yogyakarta : Andioffset. 